Kautzsch, Socin, and Koch which it has elicited will remain valuable contributions to palæography, and if it should call forth any more such solid disquisitions, science will be permanently benefited.

\section{HOOKER'S "PRTMER OF BOTANY"}

Science Priners. Edited by Professors Huxley, Roscoe, and Balfour Stewart.-." Botany." By Dr. J. D. Hooker, C.I3., P.R.S. (Lond'on: Macmillan and Co., 1876.)

$\mathrm{T} T$ is now almost universally admitted that the study of 1 botany may be made an excellent training for children; but the exient of the subject is so great, and the phraseology has become so overwhelmed with technical terms that even those who have been the most anxious to see the science generally introduced into our schools as a branch of education, are much perplexed when called upon to determine in what way it can best be taught. Some think it most prudent to confine the attention of children to such points as may be observed with the unaided eye, or at any rate to such points as only require the help of an ordinary magnifying-glass; hence they limit the teach. ing of botany to a study of the more conspicuous parts of the higher groups of vegetable life, and leave the study of physiology and histology to a more advanced age. There is, no doubt, much that can be said in favour of this view, for in order to become fully acquainted with these branches of botany a much greater experience and skill in manipulation and experiment are required, as well as the use of high magnifying powers, than, it is quite certain, a child can be expected to possess. At the same time this limitation to so small a portion of botanical science has the tendency to produce in the mind contracted ideas respecting the true scope of the subject; for to a large extent it only admits of facts being heaped upon facts, without their proper connection one with another being made manifest. It is owing to this want of concatenation in the teaching that has led many to think less highly of botany as a branch of education than they otherwise might have done, and that its introduction into schools has not met with so much success as its more sanguine advocates could have wished to see.

The "Primer" of Botany by Dr. Hooker will go far to remove these difficulties, which have hitherto stood in the way of a more successful treatment of the subject ; for in the simplest language, and with an absence of all technical terms but such as are absolutely necessary for a proper comprehension of the subject-and which, when they do occur, are always fully explained-the pupil is introduced to all the most important facts connected with structural and physiological botany. These facts, by means of a judicious arrangement and proper explanations, are made to exhibit their mutual dependence upon one another, and the work thus forms a continuous argument from beginning to end. Although the book contains only I 2 pages, and is profusely illustrated, there is hardly a point in structure or physiology that is not touched upon, and so far as the scope of the book will allow, fully explained. A further very noticeable characteristic of the "Primer" is that the pupil is instructed to draw conclusions from information derived from observation founded upon experiment as well as from direct observation.
To teachers the "Primer" will be of inestimable value, and not only because of the simplicity of the language and the clearness with which the subject matter is treated, but also on account of its coming from the highest authority, and so furnishing positive information as to the most suitable methods of teaching the science of botany, and for the want of which the instruction given in schools has hitherto been too often of a most capricious description. Again, those who have the formation or management of gardens, set aside for botanical purposes, entrusted to them, will find the list of plants at the end of the book extremely useful, as it contains those which experience has shown to afford the best examples of the particular characters it is desirable to illustrate; they are also such as may be readily procured and easily grown.

If the "Primer" has long been looked for, the high expectations which have been raised are not doomed to be cisappointed, and it may be confidently anticipated that its introduction into schools will determine very largely the direction which the teaching of botany in this country will take: for the future.

\section{A. LAWSON}

\section{OUR BOOK SHELF}

Aventures Aériennes et Expériences Mémorables des Grands Aéronamtes. Par W. de Fonvielle. Ouvrage orné de 40 gravures. (Paris: E. Plon, 1876.)

M. DE FONVIELLE'S name is no doubt famiilar to our readers as that of an experienced scientific aëronaut and writer on aëronautics. In the work before us he has traced in an interesting and instructive manner the history of ballooning from the first rude attempts to rise in the air, down to the elaborate experiments and machines which have been devised at the present day. He has evidently spent considerable pains to obtain a complete knowiedge of the history and methods of ballooning, and his scientific knowledge enables him to point out in the many experiments which have been made, the causes of failure or success. The work is evidently meant mainly for popular reading, and those who understand French will find it full of interest. The author attempts to show how practically to utilise a discovery which up to the present time has produced few practical results. He is quite opposed to all the fantastical projects which have been proposed and tried in aëronautics, and trears his subject, on the whole, in a sensible and moderate fashion, showing that those chimerical schemes have been really hindrances to the improvement of aërial navigation. He shows that important meteorological results might be obtained by properly organised ascents, and that indeed in this respect results of some importance have already been obtained. The numerous illustrations are interesting, and altogether the work may be re:arded as an important contribution to the history of aëronautics.

\section{LETTERS TO THE EDITOR}

[The Editor does not hold himself responsible for opinions expressed by his correspondents. Neither can he undertake to return. or to correspond with the writers of, rejected manuscripts. No notice is taken of anonymous communications.]

\section{New Laurentian Fossil}

Mr. JAMES Thomson, of Glasgow, who has been for some years on the out-look for fossils in the Laurentian rocks of Scotland, and has searched parts of Argyleshire, Inverness-shire, Ross-shixe, and Caithness with this object, has Iately been rewarded by the discovery, in the neighbourhood of Tarbert, 